\title{
El discurso sobre la emancipación de la mujer durante el conflicto armado interno en el Perú: memorias de las mujeres del PCP-Sendero Lu- minoso
}

\section{The discourse on the emancipation of women during the armed internal conflict in Peru: memories of the PCP-SL women}

Fiorella López López*

Pontificia Universidad Católica del Perú

\section{Resumen}

Este artículo analiza el discurso sobre la emancipación de la mujer que el Partido Comunista del Perú-Sendero Luminoso (PCP-SL) propagó con vistas a la consecución de su proyecto político armado en el contexto peruano. Son dos los objetivos planteados: determinar las razones que llevaron a que la ideología del PCP-SL convocara a una gran cantidad de mujeres y si realmente constituyó una liberación o cambio significativo en cuanto a las estructuras de género. Las fuentes utilizadas son textos bibliográficos, documentos del PCP-SL, testimonios de la Comisión de la Verdad y Recon-

* Magister en Estudios Culturales por dicha Universidad.

Correo electrónico: fiorella.lpz@gmail.com 
ciliación, y diálogos entablados con presas sentenciadas por el delito de terrorismo y recluidas en el penal de Máxima Seguridad de Santa Mónica. Este estudio encuentra que, pese a que el partido no implementó una política de género integral, permitió una participación diferente para las mujeres, la creación de nuevos roles femeninos y un cambio significativo en la vida de muchas de ellas.

Palabras clave: PCP-SL, conflicto armado interno, emancipación de la mujer, género, memoria

\section{Abstract}

This article analyzes the discourse on the emancipation of women that the Communist Party of Peru-Shining Path (PCP-SL) spread towards achieving its armed political project in the Peruvian context. The objectives of this study are to determine the reasons that led the ideology of the PCP-SL to convene a large number of women and if it really meant a liberation or a significant change in terms of gender structures. The sources used are bibliographic texts, PCP-SL documentation, testimonies of the Peruvian Truth and Reconciliation Commission (TRC) and dialogues with women who have been sentenced and imprisoned for the crime of terrorism at Santa Monica maximum security prison. This research finds that even though the PCP-SL did not introduce an integral gender policy, it allows a different kind of

122 participation for women, the creation of new feminine roles and a significant change in the life of many of them.

Keywords: PCP-SL, Peru, internal armed conflict, emancipation of women, gender, memory 


\section{Introducción}

El Conflicto Armado Interno (CAI) de 1980-2000 nos enfrenta aún a múltiples preguntas. Comienzan a emerger historias silenciadas: muchos quieren recordar y explicar lo que vivieron en sus comunidades, ciudades, e incluso dentro de las cárceles. Sin embargo, el miedo a hablar libremente de lo sucedido está aún presente, pues ha sido impuesta una memoria oficial estatal que impide que otras historias puedan ser contadas. El conflicto no ha terminado aunque dieciséis años hayan pasado desde que la guerra acabó oficialmente y trece desde que la La Comisión de la Verdad y Reconciliación (CVR) pretendió explicar las causas y dar recomendaciones para que la violencia no se vuelva a repetir. El contexto actual difiere, pero los años del CAI conservan su fuerza en la memoria de miles de peruanos y peruanas. Por ello la necesidad de continuar recuperando las historias de los propios actores de la guerra, así como de ahondar en temas escasamente discutidos hasta el momento. En particular, reconstruir las historias de los colectivos de mujeres y analizar más ampliamente los distintos roles de las mujeres en el desarrollo de la guerra, en el contexto del proyecto emancipatorio femenino del Partido Comunista del Perú-Sendero Luminoso (PCPSL), y el debate entre la izquierda democrática, el feminismo y los grupos subversivos, como un intento de sumar esfuerzos a aquel realizado por la CVR (2003) en el Informe Final.

En este trabajo me interesa enfocar la memoria silenciada de las mujeres senderistas. Ante un incremento de trabajos sobre la participación de la mujer como agente activo en la configuración de la guerra a la que dio inicio el PCP-SL en mayo de $1980,{ }^{1}$ es necesario volver a mirar los acontecimien-

1 El Partido comunista del Perú-Sendero Luminoso, organización subversiva que en mayo de 1980 declaró la lucha armada contra el Estado peru- 
El discurso sobre la emancipación de la mujer durante el conflicto armado interno...

tos, desde una perspectiva histórica y crítica, para comprender las razones por las cuales las mujeres se implicaron al igual que los hombres en un conflicto bélico y se posicionaron en base a una ideología política concreta, alejándose así del rol tradicionalmente asignado a la mujer. Este texto busca reconstruir, analizar y proponer nuevas miradas sobre la participación de la mujer en el PCP-SL a través de diferentes fuentes: textos bibliográficos, documentos del PCP-SL, testimonios de la CVR y conversaciones entabladas con presas sentenciadas por el delito de terrorismo y recluidas en el penal de Máxima Seguridad de Santa Mónica en Chorrillos.

El PCP-SL ha sido mi objeto de estudio elegido por su faceta como gestor de un discurso crítico de la subordinación de la mujer desde una perspectiva marxista. La ciudad de Lima es el referente principal de la investigación, y dos son los objetivos planteados: determinar qué llevó a que la ideología del PCP-SL convocara a una gran cantidad de mujeres y si realmente constituyó una liberación o cambio significativo en cuanto a las estructuras de género. Mi hipótesis es que, por un lado, diferentes factores contribuyeron a que el PCP-SL se posicionara en cierta medida como un partido que hacía partícipe a las mujeres de los mismos roles que a los hombres, con lo cual llegó a constituir para ellas un espacio importante de representación política. Por otro lado, pese a que el partido no implementó una política de género integral, permitió una participación diferente para las mujeres, la creación de nuevos roles femeninos y un cambio significativo en la vida de muchas de ellas. ¿Qué clase de elementos en el proyecto subversivo del PCP-.SL podría haber sido interpretados

ano, abrió un contexto de guerra que afectó al país durante dos décadas. La Comisión de la Verdad y Reconciliación (CVR) estima que la cifra de víctimas fatales de la violencia es de 69.280 personas, siendo el PCP-SL el mayor perpetrador de crímenes contra los derechos humanos (2003: Tomo I). 
como "emancipatorio" para las mujeres? ¿Qué les ofrecía el PCP-SL a diferencia de otros partidos políticos? ¿De qué maneras y en qué casos esta participación supuso no una negación del sujeto femenino, sino más bien su redefinición? ¿En base a qué tipo de exclusiones -el sujeto homosexual, la feminista "burguesa"- - se construyó el proyecto de la emancipación de la mujer? ¿En qué medida la centralidad puesta únicamente en la lucha de clases implicó una subordinación e invisibilización de las diferencias culturales, étnicas, sexuales y de género, e imposibilitó una lectura en un contexto histórico especifico? Estas preguntas puntuales han sido esenciales para los propósitos de esta investigación.

En un primer momento, recojo las representaciones que se han realizado sobre la participación de las mujeres en el PCP-SL en la prensa, la academia y ciertos grupos de poder político, con la finalidad de identificar los puntos ciegos y proponer lecturas alternativas, pues son estas las que han contribuido a construir una historia parcial sobre las causas de su militancia e imposibilitado abrir una conciencia crítica más amplia. En un segundo y tercer momento, partiendo de un recuento histórico, reconstruyo el discurso de la emancipación de la mujer formulado por el PCP-SL desde sus documentos oficiales, y analizo las razones históricas que permiten explicar una amplia participación de mujeres en el PCP-SL a diferencia de otros partidos políticos. En un cuarto momento, planteo la importancia del estudio de los testimonios de mujeres recogidos en las cárceles, en tanto constituyen una fuente importante en la construcción de la memoria colectiva. Finalmente, analizo uno de estos testimonios en tanto complementa muchas de las ideas y argumentos propuestos. En conjunto, cada una de estas partes busca contribuir a la visibilización de historias silenciadas de mujeres y la reflexión en torno al conflicto armado interno desde una perspectiva de género. Con ello se busca posibilitar otras narrativas sobre la historia reciente del conflicto 
El discurso sobre la emancipación de la mujer durante el conflicto armado interno...

armado interno, necesarias para una mejor comprensión de temas cruciales para los procesos de reconciliación en la sociedad peruana post-conflicto.

\section{Las percepciones sobre la participación de las muje- res en el PCP-SL}

La participación de las mujeres en el PCP-SL tuvo un gran impacto en la opinión pública y en el imaginario colectivo, dando lugar a una serie variada de estereotipos. Al participar activamente en el proceso de la guerra, fueron las mujeres, al igual que los hombres, responsables de muchas acciones violentas, una violencia que ha sido presentada históricamente como característica legítima de la masculinidad. Por ello, llegaron a ser caracterizadas por agentes de la policía como "más determinadas y peligrosas que los hombres", y como poseedoras de "la dicotomía de la debilidad y la dureza" (Kirk 1993: 18). ${ }^{2}$ De este modo, quedaron subsumidas bajo el estereotipo de mujeres sanguinarias. Las mujeres accedieron a puestos importantes de dirección política y militar, ${ }^{3} \mathrm{y}$ demostraron que eran tan capaces de ejercer violencia como los hombres. No obstante, más allá de poner en práctica el ejercicio de la violencia, las mujeres configuraron nuevos es-

2 Robin Kirk cita un manual de entrenamiento de la policía acerca de las mujeres subversivas que data de 1990.

3 El texto Investigación: Género y Guerrilla, elaborado en el año 2014 por las presas del PCP-SL, recluidas en el Establecimiento Penitenciario de Máxima Seguridad de Mujeres de Chorrillos, sostiene que las mujeres constituyeron un tercio de la dirección partidaria a nivel nacional y un tercio del total de los combatientes del Ejército Guerrillero Popular. 
pacios de poder, ${ }^{4}$ dando lugar a una participación protagónica que alteró, de cierta manera, un sistema de género caracterizado por la jerarquía y la discriminación que supone la subordinación de la mujer como una premisa fundamental.

A inicios de los años 80, estas mujeres llamaron poderosamente la atención, otorgándoseles un relieve mediático que intentó extender una situación de amenaza o pánico moral (Caro Cárdenas 2006: 127). Se podría proponer que el estigma social imputado se debió, en primer lugar, a la trasgresión de rol tradicional de la mujer y, en segundo lugar, a la trasgresión de los espacios que muchos concibieron como determinados a partir de categorías raciales y de clase, e incluso a patrones de belleza dominantes en la sociedad. En este segundo punto, romper la imagen estereotipada del militante de grupos subversivos, tal como se dio en algunos casos, contribuyó a la reificación de una imagen pública negativa. ${ }^{5}$ Las mujeres senderistas, de diversas maneras y en distintos grados, se convirtieron en símbolos de la maldad, la traición y la vergüenza como resultado de un proceso de estigmatización que se mantiene vigente en la actualidad.

4 Ellas accedieron a importantes puestos de dirección, así como también participaron en incursiones armadas y estrategias militares. De las tres personas que integraron el Comité Permanente, dos eran mujeres: Augusta La Torre y Elena Iparraguirre. Como parte del Buró Político estaban además Deodato y Elizabeth Cárdenas, y, en el Comité Central, ocho de las diecinueve personas que lo integraban eran mujeres.

5 Algunos casos representativos son, por ejemplo, los de Maritza Garrido Lecca y Lori Berenson. Los medios de comunicación han prestado particular interés en ellas, manifestando un abierto rechazo y ensañamiento. Ambas eran jóvenes de clase media, con educación en escuelas privadas, algo muy lejano a lo que se concebía en el imaginario popular como la "identidad” 'subversiva' de los grupos alzados en armas. 
El discurso sobre la emancipación de la mujer durante el conflicto armado interno...

En la actualidad son relativamente escasos los estudios realizados sobre las mujeres que participaron del proyecto armado que emprendió el PCP-SL. La mayor parte de nuestras referencias se hallan vinculadas a las mujeres que conformaron la cúpula del partido, sin llegar a captar el conjunto de variadas experiencias que han delineado su participación. A continuación haré un breve recuento de las interpretaciones planteadas.

La captación de las mujeres en las filas del PCP-SL ha sido pensada como una instrumentalización de la militancia femenina a partir de la canalización del odio y la frustración de la discriminación social, racial y de género. Sin embargo, ello dejaría sin explicar porqué mujeres "educadas" habrían optado conscientemente por esta vía. Ha sido pensada también dentro de los lazos familiares del matrimonio, como una lealtad al esposo y a su partido. Isabel Coral, por ejemplo, explica los vínculos del PCP-SL con las mujeres a partir de dos modalidades: "[...] el involucramiento afectivo del entorno de familiares de los alzados en armas y el involucramiento forzado de mujeres en la atención de sus necesidades de sobrevivencia" (1999: 343). Señala además su capacidad de compromiso y voluntad de lucha antes que sus capacidades teóricas y políticas. Esta es una postura que también adopta el Informe de la CVR: "[...] en todo este proceso de expansión del PCP-SL, el liderazgo femenino adquirió gran relevancia, lo cual no implica que el PCP-SL haya construido un discurso sobre el problema de la mujer, sino que utilizaba su condición de subordinación y necesidad de reconocimiento para reclutar militantes y encuadrarlas en los objetivos de su proyecto armado" (2003: Tomo III, 627).

La mayoría de estos postulados concuerda también en plantear la masculinización de las mujeres como un tipo de subordinación extrema. Robin Kirk, por ejemplo, afirma que al presenciar el modo de vida que llevaban las senderistas re- 
cluidas en el penal de Canto Grande lo que vio fue mujeres formadas como soldados, recitando himnos, gritando lemas y aplaudiendo: "Eran las legiones de hierro" (1993: 61). Una feminidad amoldada a un canon de masculinidad donde son el coraje y la resolución lo que importan. Según esta idea, las mujeres pasan por un proceso de masculinización para legitimarse en la esfera pública a través de su inserción en el desarrollo de la guerra, un tipo de masculinización que es pensada siempre como deficiente en comparación a la del hombre. Todos estos planteamientos dejan de lado las convicciones políticas por parte de las simpatizantes y militantes del PCP-SL. Cabe destacar que algunas lecturas diferentes a las ideas predominantes descritas han comenzado a plantearse en años recientes, abriendo nuevas y valiosas interpretaciones (véase Dietrich 2014; Heilman 2010).

Quiero plantear, además, que las mujeres senderistas subvierten de modo particular el orden de género, y que las interpretaciones sobre ellas no han sido abiertas a esta idea. Por una parte, las mujeres senderistas constituyen una imagen que modifica la representación pasiva de la mujer en la sociedad. La masculinidad de las mujeres del PCP-SL podría interpretarse ya no como una patología o una re-inscripción en una supremacía viril, sino más bien como una consecuencia de una rebelión social contra algunas de las normas convencionales de la feminidad. Esto sugiere que es la radical diferencia de esta imagen femenina con respecto a la tradicional lo que la hace tan difícil de representar tanto en la prensa como en los estudios académicos. Sin embargo, en la sociedad ha quedado marcada el recuerdo de la imagen — recibida con mucho impacto- de mujeres con trajes masculinos, combatiendo y empuñando armas. Se trata de una representación que ha quedado grabada, además, en innumerables consignas e imágenes de guerra por parte del PCP-SL. 
Es esta la imagen inmediata que viene a la mente cuando se piensa en mujeres senderistas, la misma que pone en duda los binarios del discurso dominante de género. Judith Halberstam (2008) recopila una serie de mitos y fantasías sobre la masculinidad y sostiene que ella no necesariamente implica poder, así como no debe ni puede ser reducida al cuerpo del hombre y a sus efectos. De acuerdo con esta idea, la masculinidad femenina nos desmiente la noción de que la masculinidad es un atributo natural del hombre, revelándolo como una construcción. Esto explicaría porqué las mujeres masculinas son representadas negativamente: "[...] las masculinidades femeninas se consideran las sobras despreciables de la masculinidad dominante, con el fin de que la masculinidad de los hombres pueda aparecer como lo verdadero" (Halberstam, 2008: 23). También indicaría que las mujeres senderistas acceden a una masculinización no deficiente en comparación a la de los hombres y que no implica necesariamente subordinación. En este sentido, las mujeres no solo están siendo castigadas y estigmatizadas por ser "terroristas" sino por haber sido, además, malas mujeres (malas madres, hijas, esposas) y por representar un reto a la idea de masculinidad. Es decir, ellas han sufrido un proceso de estigmatización mayor que la que sufren hombres militantes porque ellas no se adecúan a las normas de género tradicionales.

\section{2. "El marxismo, Mariátegui y el movimiento femenino"}

Describir el discurso senderista sobre la emancipación de la mujer peruana es una tarea esencial para comprender cuáles fueron las características que lo hizo particularmente atractivo para una amplia cantidad de mujeres. El PCP-SL elaboró una concepción de la opresión de la mujer desde una perspectiva marxista. Es decir, si bien desarrolla un 
planteamiento sobre la opresión de la mujer, no reivindica para sí ninguna postura feminista, realizando un vínculo directo entre "feminismo" y "feminismo burgués", así como entre "género" y "feminismo burgués". Elena Iparraguirre $^{6}$ ha afirmado: "[...] nunca nos hemos dado de feministas, sino la emancipación de la mujer ante la ley y ante la vida, como realidad material" (Guzmán e Iparraguirre 2002c: 89). Sin embargo, podríamos ubicar su perspectiva en la corriente de la teoría feminista marxista/ socialista, es decir, aquella que defiende la abolición del capitalismo y la implantación del socialismo como única forma de liberación de las mujeres.

Catalina Adrianzén figura como la autora del documento senderista El Marxismo, Mariátegui y el Movimiento Femenino, ${ }^{7}$ una de las primeras tentativas marxistas en intentar un análisis de la situación de la mujer peruana desde un punto de vista que toma en cuenta a la sociedad estratificada en clases como su condición fundamental. La intención principal de este texto, escrito a partir de la lectura del libro El segundo sexo de Simone de Beauvoir, fue plantear una crítica a sus

6 Elena Iparraguirre Revoredo, conocida como "Camarada Miriam", integró el Comité Permanente del PCP-SL y pasó a ser la segunda autoridad de la agrupación luego de la muerte de Augusta La Torre.

7 Este documento si bien aparece bajo su autoría, constituye un trabajo elaborado colectivamente para la dirección del partido. Elena Iparraguirre señala en la entrevista recogida por la CVR que escribió dicho texto de manera conjunta con Augusta La torre y una militante más del PCP-SL. Esta Información ha sido corroborada durante conversaciones con presas del PCP-SL recluidas en el Establecimiento Penitenciario de Máxima Seguridad de Santa Mónica en Chorrillos, quienes han sostenido además que dicho documento ha sido escrito a partir de una conferencia ofrecida por Abimael Guzmán Reinoso, líder de la organización, en setiembre de 1973. La primera edición del texto fue realizada en 1974 y la segunda en 1975. 
El discurso sobre la emancipación de la mujer durante el conflicto armado interno...

postulados y plantear unos nuevos tomando como principales referentes teóricos a Karl Marx y José Carlos Mariátegui. Se trata del documento guía para los lineamientos del PCP-SL sobre el tema de la subordinación de la mujer, cuyas ideas se encargó de difundir el Movimiento Femenino Popular (MFP), un organismo generado por el mismo partido, conformado exclusivamente por mujeres. Augusta La Torre fue la responsable de fundar este movimiento en Ayacucho a fines de la década del 60. Varios años después, en Lima, la constitución del Centro Femenino Popular daría lugar a un movimiento que tendría incidencia a nivel nacional, adoptándose este documento que serviría de guía para la acción, y acordándose un "Plan de politización" con recorridos en casi todos los departamentos del país y un "Plan de investigación" sobre la situación de la mujer (Presas del PCP-SL 2014: 3$){ }^{8}$

Elena Iparraguirre ha mencionado en su testimonio brindado a la CVR que el MFP buscó participar en todos los eventos sobre la mujer que se dieran en el país, como oyentes generando debates y repartiendo volantes, y como ponentes invitadas (Iparraguirre 2003: 10). Asimismo, la creación de un órgano de prensa que sirviera como medio de comunicación contribuyó a la difusión de las ideas del partido: la revista Rimaryña warmi ("Habla mujer") se constituyó como el vocero del MFP. El PCP-SL, por lo tanto, articuló en su discurso el problema de la subordinación femenina con el objetivo de plantearlo como un elemento clave para generar un cambio en las estructuras sociales, convocando activamente a mujeres y creando espacios de diálogo. Esta amplia cober-

8 Abimael Guzmán sobre el Movimiento Femenino Popular: "Nosotros íbamos trabajando desde Ayacucho sobre los problemas de la mujer [...]. Nosotros hemos hecho trabajo en todo el país, íbamos a todos los pueblitos, hacíamos reuniones y allí las mujeres exponían sus problemas, igual con los universitarios” (Guzmán e Iparraguirre 2002a: 71). 
tura y movilización parece haber sido un factor importante para hacer partícipe a muchas mujeres de la ideología de la organización. Haciendo referencia a una igualdad de oportunidades en la práctica del PCP-SL, a diferencia de otros partidos políticos, Iparraguirre menciona en su testimonio a la CVR (Iparraguirre, 2003: 7): “[...] ¿Patria qué cosa quería? Que las mujeres fuéramos a recolectar pollos... inaceptable. Pero en el "Comité Nacional 14 de Junio" éramos iguales que todos, hacíamos las mismas cosas".

Esta participación, sin embargo, no se ha dado de manera uniforme. Reconocer diferentes momentos, así como múltiples y distintos posicionamientos, resulta necesario para comprender las causas y motivaciones de las mujeres para haberse unido al PCP-SL. Se trata de una participación que ha variado según los distintos roles y status dentro de la organización y su convicción política. Liliam Dianderas realiza una clasificación que toma en cuenta cuatro diferentes grupos: "La Elite", "Profesionales", "Mujeres Comunes" y "Campesinas" (2004: 56) . Son estas diferencias las que permitirían rastrear los motivos por los cuales muchas mujeres desistieron de su participación, pues no constituyó un cambio positivo para todas.

Algunos testimonios recogidos por la CVR y relatos de mujeres ex militantes hablan de una serie de contradicciones existentes entre el discurso oficial y la práctica del partido, las cuales visibilizan la existencia de un doble discurso respecto de lo permitido y lo prohibido en el sistema de organización en relación a la cuestión de género y la sexualidad (Henríquez 2006: 27). Por un lado, existió una desvalorización de la mujer como figura de autoridad y se la concibió como objeto sexual (Bracco 2005: 35; Del Pino 1999: 181). Por otro lado, los valores femeninos vinculados a la maternidad fueron re-

9 Traducción mía. 
primidos, siendo las mujeres obligadas a dar en adopción a sus hijos a extraños, puesto que el PCP-SL ejercía un fuerte control sobre las relaciones familiares de sus militantes. Además, muchas mujeres continuaron estando a cargo de tareas domésticas y al cuidado de los hombres (Dianderas 2004: 59-61). En ambos casos, se afirma, existió una falsa ilusión de poder y autonomía relacionada a una serie de tensiones y contradicciones tanto al interior del PCP-SL como por parte de los miembros del partido hacia las poblaciones. Es importante tomar en cuenta este referente amplio sobre el variado tipo de participación y valoración de las mujeres sobre el PCP-SL para romper con la homogeneidad de las representaciones e identificar la singularidad de cada experiencia. Dentro de este conjunto de experiencias, el partido logró captar a muchas mujeres que manifiestan haber encontrado un espacio de representación política y relaciones de género igualitarias. A continuación, sitúo estas experiencias en relación con otros actores políticos cuyo desenvolvimiento contribuyó a definir su participación.

\section{E1 movimiento femenino, las izquierdas peruanas $y$ el PCP-SL}

Acercarnos a una nueva lectura sobre la participación de las mujeres en el PCP-SL requiere situarnos en el entramado de acciones y el contexto histórico en el que dicha participación se inscribe. Por ello, es necesario situar su participación en relación con el proceso de relacionamiento, bastante conflictivo, de los partidos políticos y movimientos de izquierda, con los diversos movimientos de mujeres en el país. Haré a continuación un recuento histórico para visibilizar tales desencuentros que contribuyeron a generar una amplia participación de mujeres en el PCP-SL. 
En el Perú, son los estudios de Virginia Vargas los que han contribuido principalmente a comprender el complejo y heterogéneo conjunto de expresiones que han dado origen e impulso al movimiento feminista en particular y al movimiento de mujeres en general. Partiendo de la distinción que propone Vargas (2008), podemos distinguir tres vertientes principales en el movimiento de mujeres del Perú: la vertiente feminista, la vertiente popular y la vertiente que emerge de los espacios políticos tradicionales. Estas a la vez se mezclan y diferencian en sus planteamientos teóricos y posicionamientos prácticos.

Con relación a ellas, Vargas señala que el surgimiento del feminismo contemporáneo en el país se encuentra estrechamente ligado a la corriente de izquierda que se conformó hacia fines de la década de los setenta, y sostiene que "La historia tanto de la vertiente feminista como de la popular está plagada de ejemplos de la ceguera de los partidos para entender la dinámica y la autonomía del movimiento" (2008: 96). Sobre dicha clasificación, Vargas aclara que en la tercera vertiente no considera a todas las mujeres que tienen un compromiso político con partidos y sindicatos. Ella plantea el siguiente motivo: "[...] no solo porque algunas no están ni siquiera mínimamente identificadas con los asuntos de la mujer, sino también porque sus prácticas sociales apuntan en otra dirección” (2008: 36). De este conjunto, señala a las mujeres de "Sendero Luminoso"10 como la expresión más extrema por considerar que tienen la más tradicional y autoritaria concepción sobre la política. Más adelante, agrega que desde una visión tradicional "[...] la vertiente feminista del movimiento de mujeres es catalogada como pequeña burguesa, y es en este término despectivo donde supuestamente residen sus limitaciones" (2008: 69).

10 Sendero Luminoso es el nombre común con el que se conoce al Partido Comunista del Perú-Sendero Luminoso. (PCP-SL). 
Es importante, sin embargo, considerar la participación de las mujeres en el PCP-SL y situarla en relación con el proceso de lo que Vargas ha denominado los "trágicos desencuentros" entre la izquierda y las diferentes expresiones del movimiento de mujeres en el país. Algunas escritoras y activistas feministas peruanas como Maruja Barrig (1993) y Narda Henríquez (2006) han llamado la atención sobre la escasez de aproximaciones al rol de las mujeres en el PCPSL. Henríquez afirma que "[...] no existe una evaluación de su desempeño ni un análisis sobre distintos tipos de militancia" (2006: 21). Barrig se remite a los motivos por los cuales considera relevante su estudio: "La militancia femenina en SL puede ser un punto de partida interesante para señalar el entrampamiento y los límites del proceso de democratización del país, los contradictorios roles que pueden jugar las mujeres en el marco de una frágil democracia y el conflicto entre dos lógicas de actuación pública femenina: la de las líderes comunales y las de las jóvenes senderistas" (1993: 97).

Los estudios académicos que abordan la participación de la mujer en el PCP-SL comienzan a desarrollarse a inicios de la década de 1990. No obstante, con anterioridad han sido planteadas algunas hipótesis. Un argumento que ha servido para explicar la afiliación de mujeres al PCP-SL es que los otros partidos políticos de la época no permitieron que las mujeres se integraran a ellos. Los partidos políticos de izquierda, tanto aquellos que aparecieron en la década de 1920 como de la más reciente llamada "nueva izquierda", significaron algún tipo de esperanza para la ampliación e inclusión de los derechos de las mujeres, los cuales se desvanecieron rápidamente debido a sus paradigmas autoritarios y excluyentes.

En 1984, Maritza Villavicencio describe así este contexto y explica que los desencuentros entre los partidos políticos de izquierda y los derechos de las mujeres "[...] tienen su origen 
en la existencia de una estructura y un discurso patriarcal en los partidos de izquierda" (1984: 6). Un patriarcalismo que forma parte de la estructura misma de la sociedad y que se evidencia, al interior de los partidos políticos, en la jerarquización de roles y en la división del trabajo. Begoña Ibarra concuerda con Villavicencio y cita parte de una entrevista suya, realizada a Alfonso Barrantes, ${ }^{11}$ que resulta esclarecedora respecto a este punto. A la pregunta de por qué no hay mujeres en puestos importantes de Izquierda Unida, Barrantes responde: "[...] es que la izquierda entre sus defectos tiene también el machismo. (...) Sendero Luminoso les lleva cuerpos de ventaja. Ha incorporado a la mujer en forma masiva (...). Desgraciadamente... Pero es que la izquierda tiene dos temores. El temor de incorporar a la mujer, que se da dentro del temor mayor de incorporar orgánicamente a las masas" (1984: 11).

La amplia incorporación de la mujer a la política partidaria no fue algo exclusivo del PCP-SL: muchos partidos políticos contaron con una gran cantidad de mujeres militantes. Vargas explica esta participación de la siguiente manera: "Muchas mujeres de diferentes sectores sociales, especialmente de clase media, sintieron que una vía para rebelarse y rechazar los estereotipos en los que estaban inmersas era unirse a los partidos políticos, particularmente los de izquierda" (2008: 50). La idea de Vargas sugiere que esta incorporación responde a una rebelión que se da principalmente a nivel personal, ante la incapacidad del Estado de expresar las exigencias y reivindicaciones de las mujeres. Bajo esta óptica, resulta necesario analizar la incorporación de la mujer en el

11 Alfonso Barrantes Lingán, abogado y político peruano de izquierda, fue el primer presidente de Izquierda Unida (IU), coalición política fundada en 1980, conformada por distintos partidos de izquierda peruanos y disuelta en 1992. Ejerció el cargo de Alcalde Metropolitano de Lima entre 1984 y 1987. 
PCP-SL no solo desde su compromiso político sino también a partir de los cambios que marcan sus relaciones sociales de género. Así, por ejemplo, cambios estructurales que han sido determinantes para generar una mayor participación política de la mujer peruana en las últimas décadas del siglo XX: el crecimiento de áreas urbanas y servicios sociales; así como la entrada masiva de las mujeres a las escuelas, universidades y al mercado de trabajo. Se debe tomar en cuenta también la influencia de fenómenos políticos, como los movimientos armados latinoamericanos. Vargas afirma lo siguiente con respecto a este periodo: "A diferencia de otros países de América Latina, como Chile, Brasil y Argentina, el reciente movimiento de mujeres del Perú aumentó en fuerza, y diversidad, no durante la dictadura, sino en el proceso de democratización que siguió a los casi doce años de gobierno militar" (2008: 51). Es este sentido, el decenio de 1980, marca el inicio del conflicto armado interno en Perú, la recuperación de un régimen democrático, y la ampliación y diversificación del naciente movimiento de mujeres. Además, fue un periodo de desarrollo de nuevos partidos políticos de izquierda y una atención acentuada en torno a la situación de la mujer por parte de estos.

Si bien algunos estudios han intentado una aproximación al perfil socio demográfico de las militantes del PCP-SL, hasta la actualidad no se ha establecido con mucha precisión sus características específicas. De acuerdo a Coral, los primeros núcleos de mujeres senderistas procedían de los sectores medios estudiantiles y profesionales, y en menor medida de los sectores urbano marginales (1999: 341). El estudio realizado por Chávez de Paz, Juventud y Terrorismo, características de los condenados por terrorismo y otros delitos, muestra que el 56.7\% de las mujeres sentenciadas entre 1983 y 1986 tenían educación superior frente a un $31.4 \%$ de los hombres en esa misma situación (1989: 43), y que no había diferencia entre hombres y mujeres en lo que respecta al promedio de edad: 26 años 
(1989: 28). Ambos datos reflejan la confluencia de diversos factores socio-culturales en la participación de la mujer en el PCP-SL.

Una situación excepcional en la participación política de la mujer durante las décadas del 1970 y 1980 en Perú, constituyó el acceso de las mujeres a roles dirigenciales en esta organización. Se ha estimado que más del $50 \%$ de su Comité Central ha estado integrado por mujeres (Barrig 1993: 96; Mávila 1992: 45). A diferencia de ello, entre los principales frentes y partidos políticos legales existentes en 1980, los tres porcentajes más altos alcanzados por mujeres en puestos de dirección han sido $12.5 \%$, 9.5\% y 7.7\% en la Unión Nacional de Izquierda (UNIR), el Partido Aprista Peruano (APRA) y Acción Popular (AP), respectivamente (Blondet y Montero 1994: 147). De acuerdo con esto, el acceso al PCP-SL puede ser visto como la obtención de un espacio de reconocimiento que explica, en parte, su presencia en el CAI, pero que refleja, también, la ausencia de espacios de representación política en el país.

A su vez, el nexo que mantuvo el PCP-SL con los diversos movimientos femeninos fue conflictivo. En el marco del desarrollo de la politización de la mujer, el PCP-SL consideraba que era necesario e imprescindible que la mujer se organice, pero solo en organizaciones de "nuevo tipo" como el Movimiento Femenino Popular. De ahí que dijera sobre las "viejas" organizaciones feministas del "viejo Estado" que "actúan como colchones de adormecimiento; tienen en el fondo planteamientos revisionistas y burgueses y sirven como instrumento de opresión y retardamiento de la mujer con el fin de alejarlas del camino que el proletariado y el pueblo han trazado con la guerra popular" (PCP-SL 1992: 15). En un artículo de febrero de 1992 del El Diario titulado "Caduco sistema genera más hambre y desocupación sobre la mujer", se argumenta que las feministas no reivindican a la 
mujer porque ellas proclaman la "liberación" y no la "emancipación" femenina, y porque su enfoque es el de género y no el de clase, llamándolas "señoronas feministas", "traficantes", "mercenarias" y "engatusadoras" (PCP-SL 1992: 15). El proyecto de la emancipación de la mujer del PCP-SL se construyó como un movimiento que excluía al denominado "feminismo burgués", pues descartaba cualquier reivindicación de género que no partiera del principio de la lucha de clases.

En la actualidad, los estudios realizados son aún insuficientes para dar cuenta de la condición de la mujer en el PCP-SL, los diversos roles que ha tenido al interior de la organización y los factores que han contribuido a su participación. La intención de una mejor comprensión de las distintas vertientes en el movimiento de mujeres, tomando en cuenta la participación de las mujeres en el PCP-SL, produce el surgimiento de nuevas interrogantes sobre cómo deben hacerse los estudios que aborden la participación política de la mujer en la historia reciente del Perú y cuáles aspectos deberían ser tomados en cuenta en el análisis. De este modo, el estudio de la participación política de la mujer en esta organización contribuye a cubrir una ausencia historiográfica, proponiendo una nueva aproximación a la construcción del movimiento feminista y del movimiento de mujeres en el Perú, lo cual a su vez resulta vital para continuar analizando las potencialidades y limitaciones del movimiento social de mujeres en el contexto peruano.

\section{Hacia una lectura de los testimonios de mujeres de- tenidas y condenadas por el delito de terrorismo}

El número reducido de trabajos sobre la participación de mujeres en el contexto de la guerra que recoja sus experiencias personales como mujeres militantes de grupos subversivos, ha significado un vacío importante en la búsqueda de 
una lectura histórica, política, más conectada con los diversos acontecimientos que marcaron su participación en los años 80 . Se olvida también el contexto social, altamente movilizado, de las décadas previas al CAI. Asimismo, la escasa bibliografía que existe sobre el contexto carcelario en Perú y, en particular, sobre la situación de las cárceles de mujeres revela la dificultad de visibilizar y enfrentar una serie de problemas que convierten a la cárcel en un espacio de sujetos cuyas historias se encuentran confinadas al silencio. En este sentido, enfocarse en los testimonios de mujeres condenadas por el delito de terrorismo permite construir lo que la investigadora colombiana Luz María Londoño denomina un "borizonte femenino de significación de la guerra". Asomarse al significado que tendría la guerra para las mujeres, implica instalar "[...] su palabra como referente central en la construcción de una nueva —y siempre mutable_ identidad" (2005: 68).

Para la autora, se trata no solo de resaltar las especificidades de su discurso y situación en el contexto de la guerra, sino de situarlos además en relación a la reconfiguración de identidades, espacios y prácticas, ocurrida en los últimos cincuenta años, que han subvertido el ámbito de los imaginarios sociales sobre el ser mujer. Una aproximación de este tipo puede aportar a un mayor entendimiento de las dinámicas de las relaciones sociales de género que se han generado en y desde el proyecto armado del PCP-SL. Por ello, recoger testimonios de mujeres en las cárceles, así como trabajar con aquellos que fueron recogidos por la CVR, permiten acercarnos a una mayor comprensión sobre el periodo de violencia acontecido en el Perú desde un lugar de enunciación distinto al acostumbrado.

Un acercamiento de este tipo permite un mayor entendimiento de las convicciones políticas por parte de las simpatizantes y militantes del PCP-SL que pude conocer cuando visité desde noviembre del 2011 hasta la primera mitad del 
El discurso sobre la emancipación de la mujer durante el conflicto armado interno...

2012 el Establecimiento Penitenciario de Máxima Seguridad de Santa Mónica en Chorrillos, al cual volví a inicios de enero 2014. Conversar con mujeres sentenciadas por su afiliación con el Movimiento Revolucionario Túpac Amaru $(\text { MRTA })^{12}$ y el PCP-SL, muchas de ellas con más de 20 años en las cárceles, me permitió confrontar algunos presupuestos sobre el tema que hasta entonces manejaba desde representaciones estereotipadas. Muchas de las vivencias relatadas estaban vinculadas a las motivaciones y experiencias de su participación en la guerra, y hacían énfasis en una conciencia social y política marcada por sus experiencias personales y por la coyuntura política de aquellos años. Algunas de ellas coincidían en una reivindicación de la participación de la mujer en la guerra, sin embargo, algunas otras identificaron determinadas contradicciones entre el discurso y la práctica en relación con la igualdad de género, y en relación con la visión ideológica del PCP-SL, como la existencia de prácticas autoritarias y jerarquizadas.

En el contexto de la cárcel, los temas urgentes remiten a los efectos del encarcelamiento: las condiciones del régimen cerrado impuesto en la década de 1990 y, actualmente, al nivel de violencia cotidiana y hacinamiento existente. Estos temas fueron recurrentes también en los testimonios brindados por las militantes del PCP-SL a la CVR, los cuales evidencian una prioridad en la agenda política de los presos. Además, muchas de ellas consideran que se han dado penas más extensas y condiciones más severas en comparación a las que cumplen los hombres. La situación política del país,

12 El Movimiento Revolucionario Túpac Amaru, organización subversiva que se funda el $1^{\circ}$ de Marzo de 1982, ingresa en 1984 a la lucha armada, convirtiéndose en un actor más del conflicto armado interno. La Comisión de la Verdad y Reconciliación (CVR) estima que el MRTA es responsable del $1.8 \%$ de violaciones a los derechos humanos cometidos en el Perú durante los años 1980 - 2000 (2003: Tomo II). 
su experiencia carcelaria, y la condición de la mujer fueron tres temas centrales de nuestras conversaciones. Las visitas al penal implicaron una serie de cuestionamientos permanentes sobre las posibilidades de comprender su vínculo con el PCP-SL sin desdeñar la voluntad, autodeterminación y agencia política individual puestas de manifiesto en la participación de cada una de ellas.

A continuación, presento el testimonio de una mujer identificada activamente con la ideología del PCP-SL, en tanto complementa muchas de las ideas y argumentos propuestos. Los temas tratados en él han sido discutidos con dos presas sentenciadas por terrorismo y recluidas en el Establecimiento Penitenciario de Máxima Seguridad de Santa Mónica en Chorrillos, quienes me han brindado una mayor comprensión de lo planteado en el testimonio en relación al discurso oficial del PCP-SL.

\section{Análisis de un testimonio}

Los testimonios de mujeres recogidos por la CVR contribuyen a una mayor comprensión de las variadas experiencias que han delineado su participación en el PCP-SL en el marco del CAI. ${ }^{13}$ Recojo uno de estos testimonios por considerarlo

13 Un total de 17, 020 personas brindaron su testimonio a la CVR, de los cuales las mujeres representan el 56,4\% del total de los declarantes (CVR: Anexo 3, 382). Si consideramos las estadísticas referidas a los testimonios recogidos en los penales, ellos suman un total de 821 declarantes, de los cuales únicamente 146 son mujeres: 128 casos cuya afiliación ha sido atribuida al PCP-SL y 18 al MRTA (CVR: Anexo 3, 375). El Centro de Información para la Memoria Colectiva y Derechos Humanos, administrado por la Defensoría del Pueblo, alberga estos testimonios sin contar con un registro oficial completo donde se detalle el tipo de participación de cada una de estas mujeres en ambos grupos subversivos. 
El discurso sobre la emancipación de la mujer durante el conflicto armado interno...

significativo y bastante singular, entre todos aquellos reunidos por la CVR, en tanto revela los marcos partidarios del PCP-SL sobre el tema de género.

El testimonio de Lucía (700086) da cuenta de la experiencia de una joven estudiante universitaria limeña, vinculada a la organización como una activista estudiantil en el área de "Prensa y Propaganda Revolucionaria", detenida en mayo de 1992 a los 24 años y condenada a treinta años de prisión. ${ }^{14}$ Presento este testimonio, poniéndolo en diálogo con el documento El Marxismo, Mariátegui y el Movimiento Femenino (PCP-SL, 1975), para describir la ideología del partido y su aplicación de la política de género. La finalidad de esta sección es partir de la experiencia singular para explorar las motivaciones que llevaron a una joven a colaborar con el PCPSL. La testimoniante narra su experiencia antes, durante y después de su paso por las aulas de la Universidad de Educación Enrique Guzmán y Valle "La Cantuta", incluyendo aspectos personales de su vida y de un conjunto de valores familiares, académicos y religiosos.

De padres limeños de izquierda y católicos, Lucía simpatizaba con Izquierda Unida (IU) y estuvo muy vinculada durante toda su secundaria con la Iglesia Católica hasta su acercamiento, a través de cursos universitarios, al marxismo. Afirma que el PCP-SL ofrecía en la universidad un tipo de participación distinta a los otros partidos políticos, más íntegra

144 y comprometida.

Lucía suscribe muchas de las ideas planteadas por el PCPSL. Retomaré las ideas principales para presentar la ideología de género y clase del partido. La primera de ellas es que

14 El nombre de la testimoniante ha sido cambiado por no contar con autorización para citarla en este trabajo. 
la politización de la mujer se entiende como un proceso de posicionamiento con respecto a su clase, un requisito previo para la igualdad de géneros. Lucía suscribe estas ideas cuando afirma que el problema de relaciones sociales no está en la dominación sexual, ni en la edad, ni en la condición social de la que uno provenga, tampoco está "en las razas"; el problema está para ella en la posición de clase que el sujeto asume en el partido:

Dentro del Partido Comunista del Perú, hombres y mujeres tenemos igual participación, no depende del sexo, no depende de la edad, no depende de la condición social de donde usted haya venido, sino depende de la posición que usted asuma $[\ldots]$ asume una posición y según eso va asumiendo mayor responsabilidad, va encarnando cada vez más las ideas, la convicción (audio del testimonio 700086).

La testimoniante sostiene además que en una sociedad sin distinción de clases dejarían de existir estos "otros" tipos de opresiones, pensadas siempre como secundarias:

Esas ideas de machismo son ideas feudales, vienen de la colonia acá en nuestro país [...] así como el racismo que con el tiempo van a desaparecer (audio del testimonio 700086). ${ }^{15}$

En esta perspectiva, una reivindicación a favor de la igualdad femenina, es también secundaria puesto que el género se subordina al orden económico y, por lo tanto, al proyecto de la revolución socialista. Por ello, Lucia dice que no se debe luchar contra el "sexo opuesto" ya que eso llama a desunir e impide que ambos puedan "luchar juntos por sus derechos":

15 Sobre el tema del racismo, Oscar Ramírez Durand, uno de los principales líderes del PCP-SL, dice lo siguiente: "[...] Gonzalo nunca lo ha tenido en cuenta, y cuando le decíamos que había racismo, nos decía que eso no le interesa al marxismo, que hay que ver la cuestión económica, la lucha de clases, él nunca ha visto lo del racismo" (CVR, Entrevista a Oscar Ramírez Durand, 4 de octubre del 2002. p. 52). 
El discurso sobre la emancipación de la mujer durante el conflicto armado interno...

Nosotros no somos feministas, nosotros vemos que el problema de la mujer es parte del problema de la sociedad, esa explotación en que vive, en que está sumida como clase, no es problema de sexo, $[\ldots]$ esos son infantilismos de burguesía (audio del testimonio 700086).

En este sentido, la igualdad de oportunidades entre hombres y mujeres que se crea al interior del PCP-SL, tal como lo entiende Lucía, motiva su decisión de participar en él. En El Marxismo, Mariátegui y el movimiento femenino se señala, respecto a los "[...] problemas íntimamente ligados a la mujer en especial: el divorcio, el matrimonio, amor, etc.” (PCP-SL 1975), que ellos no deben distraer, pues “" [... hacer tal cosa es olvidar la lucha principal y la meta fundamental, a la vez que sembrar confusión y desorientar la lucha revolucionaria" (PCP-SL 1975). Del mismo modo, Lucía explica en su testimonio el porqué todos estos aspectos relacionados al discurso sobre la emancipación de la mujer son poco conocidos: "Es que no es lo principal, la gente no conoce esos aspectos secundarios (audio del testimonio 700086)".

Plantea su postura sobre el feminismo de la siguiente manera:

Esa es una posición burguesa de personas que solamente (se) centran en que la lucha es de sexos (...) iQuieren igualdad en todo! Ellas mismas dicen igualdad en todo. Porque hay feministas y hay feministas, hay otras un poquito que ya se van a la deformación, que ya son un poquito hasta lesbianas y otras que tienen un cierto sentido social, hay de todo allí (audio del testimonio 700086).

En este punto, considero importante abordar el tema de la homosexualidad pues permite visibilizar la ausencia de una política de género integral como parte del programa de lucha de clases implementado por el PCP-SL. En el relato de Lucía, tanto el feminismo "burgués" como la homosexualidad son considerados "problemas" sociales, un producto de las 
inequidades económicas que han de ser barridos con la transformación de la sociedad. Al describir la homosexualidad como una "desviación burguesa", Lucía parece entenderla no solo como un problema social, sino como una perversión del individuo, algo que debe ser sancionado y corregido al igual que lo debe ser la delincuencia y la drogadicción:

Dentro del Partido no se consiente la homosexualidad, no se consiente la delincuencia. Tampoco se consiente la drogadicción, esas personas están como apartadas de la misma sociedad, desclasadas, no cumplen la función (audio del testimonio 700086).

Es decir, más allá de la clase por la que se luche, los homosexuales no tienen cabida dentro del proyecto revolucionario del partido: "Como clase nueva el proletariado no consiente, el obrero no consiente esas deformaciones, contranatura" (audio del testimonio 700086)".

Considera, por este motivo, que son personas que deben pasar por un proceso de reeducación:

Se les separa, no pueden estar dentro del partido (...). Se pueden reeducar, sí, pero no dentro (...) que vayan a ser comunistas, por ejemplo, que tengan responsabilidades, no, no puede ser (audio del testimonio 700086).

Si bien el testimonio de Lucía revela un discurso homofóbico fuertemente arraigado en una tradición nacional, las presas del PCP-SL plantean hoy en día que nunca hubo una posición oficial — mas sí diversas opiniones — con respecto a la homosexualidad, puesto que no era un problema apremiante en el contexto de la lucha de clases: "En cuanto al problema de las "minorías sexuales" no era un asunto que agobiara a la sociedad peruana o al pueblo peruano, efectivamente era una minoría que no afectaba al conjunto social por lo que no fue un asunto de debate como sí lo fue por ejemplo en los Estados 
El discurso sobre la emancipación de la mujer durante el conflicto armado interno...

Unidos (...) donde empezaban a reclamar sus derechos pública y abiertamente" (Presas del PCP-SL, 2014: 6). A pesar de enfatizar que los homosexuales son ciudadanos cuyos derechos debían ser respetados, el discurso revela la exclusión a la que fueron relegados. Tanto el homosexual como la feminista "burguesa" constituyen elementos excluidos que evidencian la subordinación de la opresión de género a la lucha de clases.

Veamos en qué consistía la "nueva mujer" a la que apuntaba el PCP-SL, según el testimonio de Lucía, para comprender las particularidades que configuraron la vida afectiva, sexual y reproductiva al interior del PCP-SL, y continuar ahondando en los motivos que definieron su participación. El testimonio de Lucía contiene algunas especificaciones en cuanto al desarrollo de las cualidades del arquetipo ideal de persona socialista, cualidades que permiten que mujeres y hombres puedan tener las mismas condiciones y oportunidades:

Una tara de lo viejo por ejemplo es donde las mujeres cocinan, además de sus tareas políticas ella cocina, lava, se encarga de los hijos, agarra el hombre viene y le pega, eso es lo viejo. Eso no se permite ya en lo nuevo, (...) (se trata de) asumir las responsabilidades por igual (audio del testimonio 700086).

De acuerdo con esto, el PCP-SL proponía la trasgresión del rol tradicional de la mujer a través de una ruptura con aquellas tareas y roles vinculados a la esfera privada, principalmente

148 el cuidado del hogar y la familia. Lucía explica además que dentro del partido existía una serie de principios a partir de los cuales se consideraba como acciones a ser sancionadas la poligamia, el adulterio y el maltrato a las mujeres. ${ }^{16}$ Para ella, estas situaciones impedían el "correcto desarrollo" de las

16 Se trata de las "tres reglas de oro" y las "ocho advertencias", normas de disciplina formuladas por Mao Tse-tung y retomadas por el PCP-SL 
relaciones que debían darse entre hombres y mujeres. Dice también tener conocimiento de los juicios que se realizaban en el campo, los cuales considera justificados debido a que buscaban corregir y sancionar a aquellas personas que no eran "sinceras". Se trataba de un tratamiento correctivo, que tenía como objetivo resolver los conflictos y que se realizaba tanto entre los miembros del partido como en relación con las poblaciones locales; para Lucía significaba la aplicación del discurso del PCP-SL a la relación entre hombres y mujeres. Podemos ver cómo esta idea se complementa con las de otras presas del PCP-SL. Una de ellas, Lorena, (entrevista, Lorena, abril 9 de 2013) ${ }^{17}$ sostiene que la mujer "de nuevo tipo" no es solo más igual a su pareja en el ámbito doméstico sino que además es más "proletaria". Según esta idea, el "sentimiento revolucionario" debe ser un sentimiento "colectivo", "solidario" y no la devoción a una sola persona.

Lucía, en consonancia con estas ideas, plantea: "Nuestro lema es "primeros en el sacrificio y últimos en el beneficio" Yo no estoy para servirme a mí misma sino para servir a los demás (audio del testimonio 700086)".

Si bien el PCP-SL afirma que sobre las relaciones personales no especificó política alguna, sí existían consideraciones internas que debían tomarse en cuenta. ${ }^{18}$ Sobre la relación entre ella y su pareja, Lucía afirma que se trataba de una relación de

para guiar al Ejército Guerrillero Revolucionario. Entre estos principios figuraba la norma de "No tomarse libertades con las mujeres".

17 El nombre real ha sido cambiado para proteger la identidad de la testimoniante.

18 Las presas del PCP-SL señalan que en el partido no se han establecido normas destinadas a regular las uniones de pareja ni la vida sexual, pues las relaciones debían ser libremente decididas (Presas del PCP-SL recluidas en el Establecimiento Penitenciario de Máxima Seguridad de Mujeres de Chorrillos 2014: 5-6). 
El discurso sobre la emancipación de la mujer durante el conflicto armado interno...

respeto mutuo, y que era fundamentalmente política: " $\mathrm{El}$ su trabajo, yo mi trabajo y la relación era política, más que todo, si sirve a lo nuevo, sirve mucho más". Además, explica:

Se puede tener esa relación por esa práctica cotidiana en la vida que en común llevamos, entonces en eso va naciendo, pero ese amor tiene un sello de clase [...] la cuestión es que sirva pues al objetivo que uno tiene (audio del testimonio 700086).

La relación debía servir para que ambos se asistan y cumplan su tarea revolucionaria, el fin que media y da sentido a la unión de dos personas. El PCP-SL parecía así querer abarcar los diversos ámbitos en las vidas de sus militantes, planteando incluso que la relación de pareja sea en atención a un interés mayor: "La mujer no podía servir a un hombre puesto que debía servir al partido (audio del testimonio 700086)".

La finalidad de servir a la "revolución" permite explicar, una vez más, la unión en matrimonio de dos personas dentro del partido. Lucía señala sobre este punto que se trataba de una relación consolidada, por la cual existía también una reglamentación. Las parejas que se casaban lo hacían con la ley y a nombre de la dirección del partido:

Era a nombre de la dirección del Partido que es el Presidente Gonzalo. Y era una relación muy fuerte, no era que yo me caso hoy y me divorcio mañana, que estoy con uno, estoy con otro, eso no se permitía, si se daban problemas se les veía, [...] se les combatía ideológica, políticamente los problemas (audio del testimonio 700086).

Lucía menciona que existía una ceremonia especial para el matrimonio:

Los llamados "comisarios políticos" eran los encargados [...] (se realizaba) como si fuera ante un juzgado por civil, a nombre de la dirección del Partido que era el Presidente Gonzalo (audio del testimonio 700086). 
El acta de celebración de matrimonio del PCP-SL (19?), declara que la relación entre un hombre y una mujer entendida como "la más directa y estrictamente humana" debe coadyuvar a la brega que ambos realizan por la revolución. ${ }^{19}$ Esta dimensión colectiva se aplica también al tratamiento de la maternidad, comprendida por el PCP-SL como una condición secundaria en la vida de las mujeres, puesto que lo fundamental es su ser social y político. Al referirse a este tema, Lucía reafirma una vez más la libertad que el partido otorgaba a las mujeres:

Era libertad de tener o no tener hijos, eso nosotros lo planteamos. (...) Daba libertad, no es como la Iglesia (...) hay libertad del aborto o de no abortar (audio del testimonio 700086).

Respecto a la maternidad, las presas del PCP-SL sostienen que no había norma alguna sobre tener o no hijos: “[...] el 60\% de las militantes y combatientes tenían hijos y en la guerra o los tenían consigo o los dejaban con sus familiares, en algunos casos entregaban sus hijos a las masas de los Comités Populares" (Presas del PCP-SL, 2014: 5-6). La lectura que ellas realizan de estos hechos se encuentra mediada por el fin supremo que para el PCP-SL es la "revolución", lo cual podría interpretarse como aquello que les ha imposibilitado reconocer, procesar y validar muchas situaciones particulares de afecto. ${ }^{20}$ En esta

19 Abimael Guzmán sobre este punto: "Hemos tenido un sistema para nuestros matrimonios, hemos establecido cómo casarnos unos con otros, y qué cosas les leíamos, por ejemplo un texto de Marx, y luego un texto de Mariátegui” (Guzmán e Iparraguirre 2002b: 79).

20 En el Establecimiento Penitenciario, las presas me hablaron de sus afectos, sus relaciones familiares y políticas, de su vida cotidiana en el penal y de sus opiniones con respecto a la coyuntura política actual. Percibí constantemente la tensión entre una perspectiva individual y otra partidaria, donde terminaba priorizándose la posición oficial de la organización. 
línea, el PCP-SL ha rendido homenaje a la madre "[...] combatiente del pueblo, que no se doblega ante la pérdida de un hijo que entregó a la revolución, pues para ella sus hijos son todos los hijos del pueblo" (PCP-SL 1988: 2).

El testimonio presentado revela la experiencia particular de una mujer que encontró en el PCP-SL la oportunidad de construir una identidad propia, de mujer y activista política, y un proyecto colectivo del cual ser parte, con expectativas particulares respecto de su condición social y de género. Si bien se trata de una experiencia singular, podemos pensarla como representativa de lo que pudo haber sido la experiencia de muchas otras dentro del PCP-SL. Haber encontrado un espacio de representación política y una mejora en los niveles de subordinación en comparación con sus anteriores modos de vida, parecen haber sido dos factores decisivos para la participación de las mujeres en esta organización.

\section{Conclusiones}

La presencia de las mujeres en el PCP-SL desestabilizó los conceptos dominantes de la condición femenina, en modos particulares. Ingresar en la militancia senderista tuvo múltiples significados y consecuencias de vida. En este contexto, la resignificación del sujeto femenino planteada en los documentos y testimonios considerados en este artículo, generó expectativas con respecto a la igualdad de género y a la posibilidad de nuevas relaciones entre hombres y mujeres al interior del partido. No obstante, estas expectativas fueron frustradas por el patriarcalismo prevaleciente, y por efecto del pensamiento hegemónico, fuertemente anclado en relaciones de poder, de la ideología senderista. Por una parte, diferentes factores contribuyeron a que el PCP-SL se posicionara como un partido que prometía a las mujeres los mismos roles que a los hombres, llegando a crear en efecto un espacio de representación políti- 
ca para ellas. No solo construyó un discurso de incorporación de la mujer con el objetivo de plantearlo como un elemento clave para propiciar el cambio en las estructuras sociales, sino que en la práctica les brindó espacios de reconocimiento que otros partidos políticos les negaba. Por otra parte, pese a que el partido no tenía una política de género comprometida con un verdadero cambio en las estructuras de género, permitió la creación de nuevos roles femeninos y un cambio significativo en la vida de muchas de ellas. El testimonio de Lucía permite visibilizar una serie de características que hicieron del PCPSL, a pesar de evidentes contradicciones, un partido atractivo para mujeres que buscaban un espacio de reivindicación política. Quedan abiertas muchas preguntas sobre la participación de las mujeres en el PCP-SL, las particularidades de los diferentes roles que tuvieron dentro del partido en Lima como en las distintas regiones, vinculándose desde sus propios contextos. Continuar ahondando en las causas y motivaciones de este vínculo requiere de investigaciones que propicien debates en busca de nuevas narrativas, que incorporen a los diferentes actores implicados y que visibilicen memorias silenciadas que nos confrontan con una serie de problemáticas vigentes en la sociedad actual.

Mi agradecimiento al Grupo Memoria del Instituto de Estudios Peruanos (IEP) por permitirme presentar una versión previa de este artículo en el año 2012 y a mis profesores de la maestría en Estudios Culturales (PUCP), en especial a Víctor Vich, Francesca Denegri y Rocío Silva Santisteban, por su valioso acompañamiento y motivación en el desarrollo de esta investigación. Agradezco también a Alexandra Hibbett, Marie Manrique, Giancarlo Cornejo, Carolina Vera y Ricardo Caro Cárdenas, por sus comentarios, ideas y sugerencias que permitieron mejorar este texto. Finalmente, mi gratitud a las mujeres entrevistadas en la cárcel, por compartir su tiempo y sus historias conmigo.

Recibido: 18 de agosto del 2015

Aprobado: 20 de octubre del 2015 
El discurso sobre la emancipación de la mujer durante el conflicto armado interno...

\section{Bibliografia}

\section{Fuentes primarias}

Comisión de la Verdad y Reconciliación. Lima: Centro de Información para la Memoria Colectiva y Derechos Humanos - Defensoría del Pueblo

2002 Testimonio 700086. 22 de septiembre.

2002a Entrevista a Abimael Guzmán Reinoso y Elena Iparraguirre. 21 de octubre.

2002b Entrevista a Abimael Guzmán Reinoso y Elena Iparraguirre. 29 de octubre.

2002c Entrevista a Abimael Guzmán Reinoso y Elena Iparraguirre. 6 de noviembre.

2002 Entrevista a Oscar Ramírez Durand. 4 de octubre.

2003 Entrevista a Elena Iparraguirre. 12 de marzo.

\section{Entrevistas}

2013 Lorena, 9 de abril.

Fuentes secundarias

ADRIANZÉN, Catalina

1975 "El marxismo, Mariátegui y el movimiento femenino". Sol Rojo. Consulta: 5 de agosto de 2015.

$<$ http://www.solrojo.org/pcp_doc/pcp_0475.htm> 
BARRIG, Maruja

1993 "Liderazgo femenino y violencia en el Perú de los 90”. Debates en Sociología. Lima, número 18, pp. 89112.

BLONDET, Cecilia y Carmen MONTERO

1994 La situación de la mujer en el Perú, 1980-1994. Lima: Instituto de Estudios Peruanos.

BRACCO, Lucía

2005 "Feminidad en mujeres que cumplen condena por el delito de terrorismo". Tesis de licenciatura en psicología. Lima: Pontificia Universidad Católica del Perú, Escuela de Graduados.

CARO CÁRDENAS, Ricardo

2005 "Ser mujer, joven y senderista: memorias de género y pánico moral en las percepciones del senderismo". Alpanchis. Lima, número 67, pp. 125-156.

\section{CHÁVEZ DE PAZ, Dennis}

1993 Juventud y terrorismo. Características sociales de los condenados por terrorismo y otros delitos. Lima: Instituto de Estudios Peruanos.

\section{COMISIÓN DE LA VERDAD Y RECONCILIACIÓN}

2003 Informe Final de la Comisión de la Verdady Reconciliación. Lima: CVR.

CORAL, Isabel

"Las mujeres en la guerra: impacto y respuestas". En Stern, Steve (editor). Los Senderos Insólitos del Perú: guerra y sociedad. Lima: Instituto de Estudios Peruanos y Universidad San Cristóbal de Huamanga.

DIANDERAS, Liliam

2004 "The paradoxical role of women within Sendero Luminoso: The myriad reasons behind their refu- 
El discurso sobre la emancipación de la mujer durante el conflicto armado interno...

sal to continue fighting". Tesis de maestría. San José: Universidad de Costa Rica.

DIETRICH, Luisa

2014 "La "compañera política". Mujeres militantes y espacios de "agencia" en insurgencias latinoamericanas". Revista Colombia Internacional. Bogotá, número 80, pp. 83-133.

HALBERSTAM, Judith

2008 Masculinidad femenina. Barcelona: Egales.

HEILMAN, Jaymie Patricia

2010 "Family Ties: The Political Genealogy of Shining Path's Comrade Norah". Bulletin of Latin American Research. Cambridge, volumen 29, número 2, pp. 155-169.

HENRÍQUEZ, Narda

$2006 \quad$ Cuestiones de género y poder en el conflicto armado en el Perú. Lima: Ciencia Tecnología e Innovación del Perú.

IBARRA, Begoña

1984

"Desde Mama Ocllo a la lucha popular". La República. Lima, 25 de agosto, pp. 7-13. Suplemento especial.

KIRK, Robin

Grabado en piedra: las mijeres de Sendero Luminoso. Lima: Instituto de Estudios Peruanos.

LONDOÑO, Luz María

2005 "La corporalidad de las guerreras: una mirada sobre mujeres combatientes desde el cuerpo y el lenguaje". Revista de Estudios Sociales. Bogotá, número 21, pp. 67-74.

MÁVILA, Rosa

1992 "Presente y futuro de las mujeres de la guerra". Quehacer. Lima, número. 79 , pp. 44-49 
PCP-SL, PARTIDO COMUNISTA DEL PERÚ

1992

"Caduco sistema genera más hambre y desocupación sobre la mujer". El Diario. Lima, 21 de febrero, p. 15.

1988

"Por la Emancipación de la Mujer". El Diario. Lima, 13 de marzo. Suplemento especial.

19 ?

"Acta de celebración de matrimonio". Sol rojo. Consulta: 5 de agosto de 2015 <http://www.solrojo. org/pcp_doc/pcp_actadec.htm.>

PRESAS DEL PCP-SL RECLUIDAS EN EL ESTABLECIMIENTO PENITENCIARIO DE MÁXIMA SEGURIDAD DE MUJERES DE CHORRILLOS

2014 "Investigación: Género y Guerrilla". Lima. Documento no publicado.

PINO, Ponciano del

1999 "Familia, cultura y "revolución". Vida cotidiana en Sendero Luminoso" En STERn, Steve (editor). Los Senderos Insólitos del Perú: guerra y sociedad. Lima: Instituto de Estudios Peruanos y Universidad San Cristóbal de Huamanga.

VARGAS, Virginia

2008 Feminismos en América Latina. Su aporte a la política y a la democracia. Lima: Universidad Nacional Mayor de San Marcos, Programa Democracia y Transformación Global y Centro de la Mujer Flora Tristán.

VILLAVICENCIO, Maritza

1984

"Mujer y Política". La República, Lima, 25 de agosto, pp. 5-6. Suplemento especial. 